\title{
Effects of Pruning on the Apple Tree: from Tree Architecture to Modeling \\ D. Fumey ${ }^{1 \mathrm{ab}}$, P.E. Lauri ${ }^{1 \mathrm{a} *}$, Y. Guédon ${ }^{1 \mathrm{~b}}$, C. Godin ${ }^{1 \mathrm{c}}$, E. Costes ${ }^{1 \mathrm{a}}$.
}

${ }^{1}$ UMR DAP CIRAD/INRA/Montpellier SupAgro/UMII,

a INRA, Equipe Architecture et Fonctionnement des Espèces Fruitières, Montpellier, France

${ }^{\mathrm{b}} \mathrm{CIRAD},{ }^{\mathrm{c}}$ INRIA, Equipe Virtual Plant, Montpellier, France

Keywords: Malus x domestica Borkh, Structure-Function Plant Model, tree training, pruning.

\begin{abstract}
Arboricultural practices such as pruning, artificial bending or fruit thinning are crucial interventions in orchard management and are used for controlling tree size, penetration of light into the canopy and the equilibrium between vegetative and reproductive growth. The aim of this project is to explore the possibility of integrating such practices in a model of apple tree development. To this end we designed field experiments to study the effects of pruning (thinning or heading cuts) on two apple cultivars with contrasted architecture, 'Fuji' and 'Braeburn'. The results of these first experiments showed that the studied cultivars had significantly different reactions to pruning: 'Braeburn' trees were penalized more than 'Fuji' trees in terms of the total number of internodes despite the fact that a greater number of internodes had developed. Thinning cuts of laterals tended to be compensated by an increase in lateral branching. Results also indicated that trees which had been pruned tended to develop trunks with similar number of internodes than control trees (which were not pruned). These experiments constitute a first step for assessing the rules underlying tree responses to pruning, which will be further integrated in a model of growth.
\end{abstract}

\section{Introduction}

L-systems are being increasingly used to model the development of plants in agronomical applications (e.g. ADEL-maize, Fournier et al., 1999; L-Peach, Allen et al., 2005, Lopez et al., in press). Following this trend, we devised an L-system-based simulation project of the development of apple tree architecture. This approach features a new combination of stochastic and mechanistic models describing branching patterns and branch bending due to gravity (Smith et al., 2007, Costes et al., in press). The model, called MappleT, does not take into account arboricultural practices such as pruning, artificial bending or fruit thinning. Nevertheless, these methods of pruning are crucial interventions in the management of orchards and are used for controlling tree size, light penetration within the canopy and the equilibrium between vegetative and reproductive growth. Previous studies have analyzed tree responses to pruning and impacts on fruiting (Saure, 1987; Marini, 1987; Li et al., 2003) but few have dealt with tree responses in terms of architectural development. The aim of this project is to integrate pruning techniques into a reactive model of tree growth. This paper describes the field experiments that were designed to study pruning effects on two apple cultivars with contrasted architecture, 'Fuji' and 'Braeburn'. 


\section{Materials and Methods}

To constitute the data pool necessary for the quantification of the pruning responses in the apple tree, two cultivars were chosen, 'Fuji' and 'Braeburn'. This choice was based on two main reasons. First, they were already studied in our research team and therefore allowed us to benefit from large architectural databases collected over several years and extensively explored (Costes et al., 2003; Renton et al., 2006; Massonnet, 2008). Second, 'Fuji' and 'Braeburn' have contrasted architecture: 'Fuji' belongs to type IV according to Lespinasse typology and is characterized by a high extinction and a high awakening of latent buds and 'Braeburn' belongs to type III, but with a branching pattern similar to a type II (Lauri et al., 1997; Costes et al., 2003).

Trees were grafted onto M9 rootstock and planted in March 2007 at INRA Montpellier experimental field (south-east France, $43^{\circ} 36^{\prime} \mathrm{N} 3^{\circ} 58^{\prime} \mathrm{W}$ ). Forty trees per treatment were planted at $5 \times 2 \mathrm{~m}$ apart, in a complete randomized design. One main shoot per tree was left to develop after grafting. Two pruning treatments were applied in August 2007, i.e. during the first year of growth: heading cuts of the trunk (HCT; which reduce the length of the trunk by ca. 50\% of their internodes at the time of pruning) and thinning cuts of the laterals (TCL; which completely remove all current lateral branches; terminology according to Barritt, 1992) (Fig.1). Control trees (C) were left without any pruning.

Trees were entirely described according to the Multiscale Tree Graph formalism (Godin and Caraglio, 1998) in July 2007 (before pruning) and in December 2007, after the end of the growth season. Tree topology was decomposed into four organization levels as previously described (Costes et al., 2003): tree, axis, growth unit (GU) and internode. Several geometrical features were collected: length, number of internodes, basal and top diameters of all axes more than $5 \mathrm{~cm}$. A set of variables describing primary growth, secondary growth and branching were extracted from the database with V-Plants software (formally AMAPmod; see http://www-sop.inria.fr/virtualplants). The impact of cultivar and pruning treatments were then analyzed focusing on three variables: the total number of internodes, the basal diameter and the number of lateral branches, using a twoway ANOVA. When results were significant, the Newman-Keuls multiple mean comparison test was carried out. These statistical analyses were performed using Statistica ${ }^{\circledR}$ version 7.1.

\section{Results}

During the extraction procedure internodes were classified in three categories (Fig. 1): those developed before pruning; those removed by pruning and those newly developed after pruning. For Control trees, this last category includes all internodes developed after pruning time.

Whatever the treatment, 'Braeburn' trees developed more internodes than 'Fuji' trees (Fig. 2). In 'Fuji', there was no significant difference in the total number of internodes per tree (including those removed) between HCT and TCL compared to C (Fig.2). By contrast, for 'Braeburn', the total number of internodes decreased on HCT and TCL compared to C (Fig.2). However, there was no significant differences between HCT, TCL and C trees in either cultivar when only trunk internodes were considered (Fig.3).

When looking at branching, similar difference between cultivars was found as for the number of internodes: 'Braeburn' showed a higher number of lateral branches than 'Fuji' (Table 1). This difference mainly resulted from a higher number of laterals 
developing after pruning time. The TCL treatment induced an increase in the number of laterals compared to $\mathrm{C}$, but the reaction was extremely different between the two cultivars: 'Braeburn' developed more laterals after pruning than 'Fuji'. When compared to $\mathrm{C}$ trees the response to HCT also differed between cultivars, with no difference in the number of laterals for 'Fuji' and a significant decrease for 'Braeburn'.

Regarding secondary growth, 'Braeburn' showed larger basal diameters than 'Fuji', but this was observed only in C and HCT trees (Table 2). Whatever the cultivar, both HCT and TCL treatments induced a decrease in the tree basal diameters when compared to $\mathrm{C}$. The response to TCL treatments was the most pronounced and, for this technique, there was no significant difference between the cultivars.

\section{Discussion}

The present results show significantly different reactions to pruning in the two studied cultivars. In particular, pruning treatments decreased the total number of internodes developed within the growing season in 'Braeburn' trees but not in 'Fuji' trees. However, in both cultivars, the pruning treatments did not change the total number of internodes of the trunk, suggesting that tree growth potential was attributed to this axis with the highest priority. Pruning treatments, especially thinning cuts, tended to be compensated by an increase in lateral branching; this reaction was particularly pronounced for 'Braeburn' trees which developed a high number of lateral branches after pruning. In both pruning treatments, these intense responses did not allow the pruned trees to reach basal diameters similar to those of the Control trees. Indeed, the decrease of the basal diameter in both pruning treatments may be related to the decrease of the number of long lateral branches developed after pruning (data not shown).

These experiments constitute a first step for assessing the rules underlying apple tree responses to pruning. They also raise new questions with respect to growth distribution in trees, in terms of number of shoots, branch positions along the parent shoot and priority between shoots. This knowledge will be further integrated in a stochastic formalization of the competition between the meristems in the plant, in a model of growth reactive to pruning interventions we are presently developing.

\section{Acknowledgements}

This research is part of D. Fumey Ph.D, and is funded by grants from FAFSEA (Fonds national d'assurance formation des salariés des exploitations et entreprises agricoles), ENESAD (Etablissement national d'enseignement supérieur agronomique de Dijon) and CIFRE (Convention Industrielle de Formation par la Recherche). We acknowledge G. Garcia, S. Feral and S. Martinez for their contribution to field measurements and technical assistance in the orchard.

\section{References}

Allen, M.T., Prusinkiewicz, P. and DeJong, T.M. 2005. Using L-systems for modeling source-sink interactions, architecture and physiology of growing trees, the L-PEACH model. New Phytologist 166:869-880.

Barritt, B.H. 1992. Intensive orchard Management: A Practical Guide to the Planning, Establishment, and Management of High Density Apple Orchards, Good Fruit Growers, $211 \mathrm{pp}$.

Costes, E., Sinoquet, H., Kelner, J.J. and Godin, C. 2003. Exploring within tree architectural development of two apple tree cultivars over 6 years, Ann. Bot. 91:91-104. 
Costes, E., Smith, C., Renton, M., Guedon, Y., Prusinkiewicz, P. and Godin, C. in press. MAppleT: Simulation of apple tree development using mixed stochastic and biomechanical model. Functional Plant Biology.

Fournier, C. and Andrieu, B. 1999. ADEL-maize: a L-system based model for the integration of growth processes from the organ to the canopy. Application to regulation of morphogenesis by light availability. Agronomie 19:313-327.

Godin, C. and Caraglio, Y. 1998. A multiscale model of plant topological structures, J. theor. Biol. 191:1-46.

Lauri, P.E., Térouanne, E. and Lespinasse, J.M. 1997. Relationship between the early development of apple fruiting branches and the regularity of bearing - An approach to the strategies of various cultivars. J. Hort. Science 72(4):519-530.

Li, K.T., Lakso, A., Piccioni, R. and Robinson, T. 2003. Summer pruning effects on fruit size, fruit quality, return bloom and fine root survival in apple trees. J. Hort. Sci. Biotech. 78:755-761.

Lopez, G., Favreau, R.R., Smith, C., Costes, E., Prusinkiewicz, P. and Dejong, T. in press. Integrating simulation of architectural development and source-sink behaviour of peach trees by incorporating Markov chains and physiological organ function submodels into L-PEACH. Functional plant Biology.

Massonnet, C., Regnard, J.L., Lauri, P.E., Costes, E. and Sinoquet, H. 2008. Contributions of foliage distribution and leaf functions to light interception, transpiration and photosynthetic capacities in two apple cultivars at branch and tree scales. Tree Physiol. 5:665-678.

Marini, R.P. and Barden, B.A. 1987. Summer pruning of apple and peach trees. Hort. Rev. 9:351-375.

Renton, M., Guédon, Y., Godin, C. and Costes, E. 2006. Similarities and gradients in growth unit branching patterns during ontogeny in 'Fuji' apple trees: a stochastic approach. J. Exp. Bot. 57:3131-3143.

Saure, M.C. 1987. Summer pruning effects in apple - a review. Scientia Hort. 30:253-282.

Smith, C., Guedon, Y., Prusinkiewicz, P., Godin, C. and Costes, E. 2007. Simulation of apple tree development using a mixed statistical and biomechanical models. Proc. Functional Structural Plant Models. Napier, New Zealand, 4-9 Nov. p. 131-134.

\section{Tables}

Table 1. Number lateral branches (mean \pm SD) per pruning treatment for 'Fuji' and 'Braeburn' apple cultivars.

\begin{tabular}{cccccc}
\hline $\begin{array}{l}\text { Cultivars and } \\
\text { Pruning treatments }\end{array}$ & before & removed & after & total \\
\hline \multirow{2}{*}{ 'Fuji' } & C & $12.68 \pm 3.07$ & - & $1.83 \pm 2.83 \mathrm{~d}^{*}$ & $14.51 \pm 3,87 \mathrm{~d}^{*}$ \\
& HCT & $13.63 \pm 2.89$ & $1.20 \pm 2.05$ & $2.20 \pm 1.54 \mathrm{~d}$ & $17.03 \pm 3,38 \mathrm{~d}$ \\
& TCL & $9.08 \pm 3.15$ & $5.75 \pm 3.18$ & $5.35 \pm 4.56 \mathrm{c}$ & $20.18 \pm 6.25 \mathrm{c}$ \\
\hline \multirow{4}{*}{ 'Braeburn' } & $\mathrm{C}$ & $15.05 \pm 3.74$ & - & $13.61 \pm 6.21 \mathrm{~b}$ & $28.66 \pm 6.91 \mathrm{c}$ \\
& HCT & $12.28 \pm 2.97$ & $3.33 \pm 3.76$ & $5.58 \pm 4.69 \mathrm{c}$ & $21.18 \pm 5.77 \mathrm{~b}$ \\
& TCL & $7.38 \pm 3.01$ & $8.82 \pm 3.15$ & $23.28 \pm 6.35 \mathrm{a}$ & $39.49 \pm 7.87 \mathrm{a}$ \\
\hline
\end{tabular}

${ }^{*}$ Within a column, a same letter indicates no significant difference between mean values according to the Newman-Keuls test. 
Table 2. Basal diameter of trunk ( $\mathrm{cm}$, mean $\pm \mathrm{SD}$ ) per pruning treatment for 'Fuji' and 'Braeburn' apple cultivars.

\begin{tabular}{|c|c|c|c|c|}
\hline \multirow{2}{*}{$\begin{array}{l}\text { Cultivars and } \\
\text { Pruning } \\
\text { treatments }\end{array}$} & \multicolumn{2}{|c|}{ 'Fuji' } & \multicolumn{2}{|c|}{ 'Braeburn' } \\
\hline & $\mathrm{n}^{1}$ & $\begin{array}{l}\text { Basal diameter } \\
\qquad(\mathrm{cm})\end{array}$ & $\mathrm{n}^{1}$ & $\begin{array}{l}\text { Basal diameter } \\
(\mathrm{cm})\end{array}$ \\
\hline $\mathrm{C}$ & 41 & $2.15 \pm 0.26 b^{*}$ & 41 & $2.27 \pm 0.21 \mathrm{a}$ \\
\hline HCT & 40 & $1.83 \pm 0.29 \mathrm{~d}$ & 40 & $2.02 \pm 0.27 \mathrm{c}$ \\
\hline TCL & 40 & $1.78 \pm 0.17 \mathrm{~d}$ & 39 & $1.78 \pm 0.20 \mathrm{~d}$ \\
\hline
\end{tabular}

${ }^{\mathrm{T}}$ Number of tree per pruning treatments.

*A same letter indicates no significant difference between mean values according to the Newman-Keuls test.

\section{Figures}

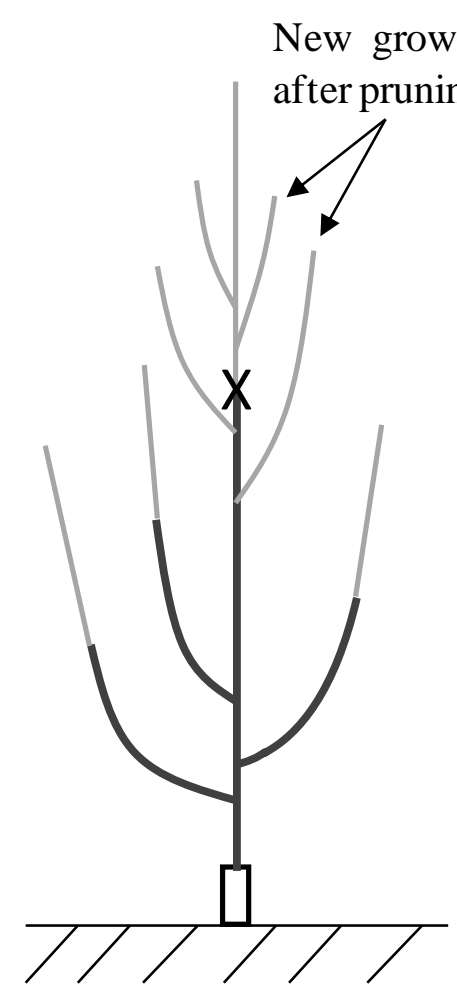

$\mathrm{C}$

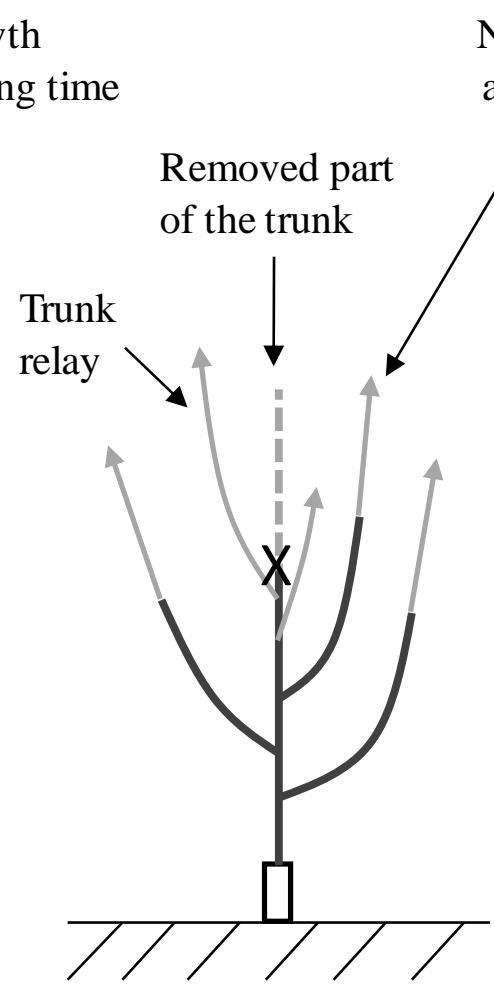

$\mathrm{HCT}$
New growth

after pruning

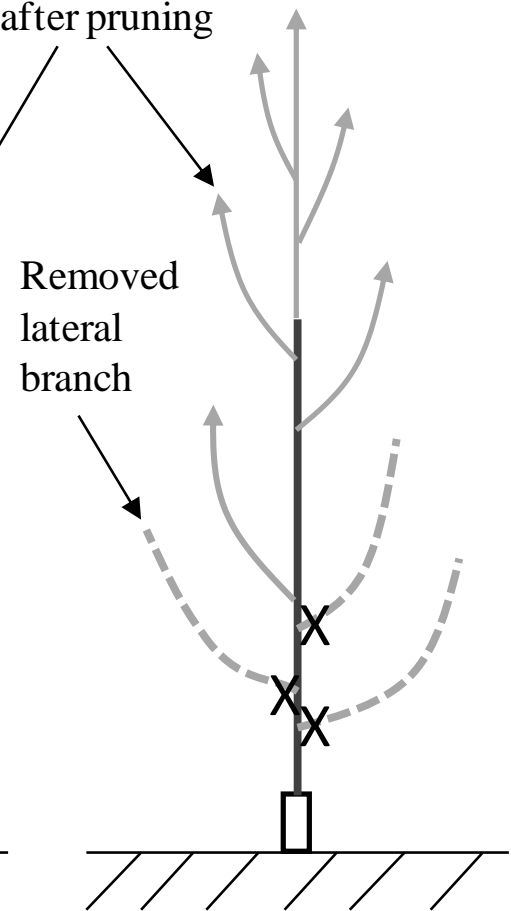

TCL

Fig. 1 Representation of control trees (C) and the two treatments: heading cut of trunk (HCT) and thinning cuts of lateral branches (TCL). Three pools of internodes were defined: internodes developed before pruning (continuous black line), removed internodes (dotted grey line), and new internodes developed after pruning (continuous grey line) for $\mathrm{HCT}$, and TCL, and after the pruning time for $\mathrm{C}$. X: pruning cut. 


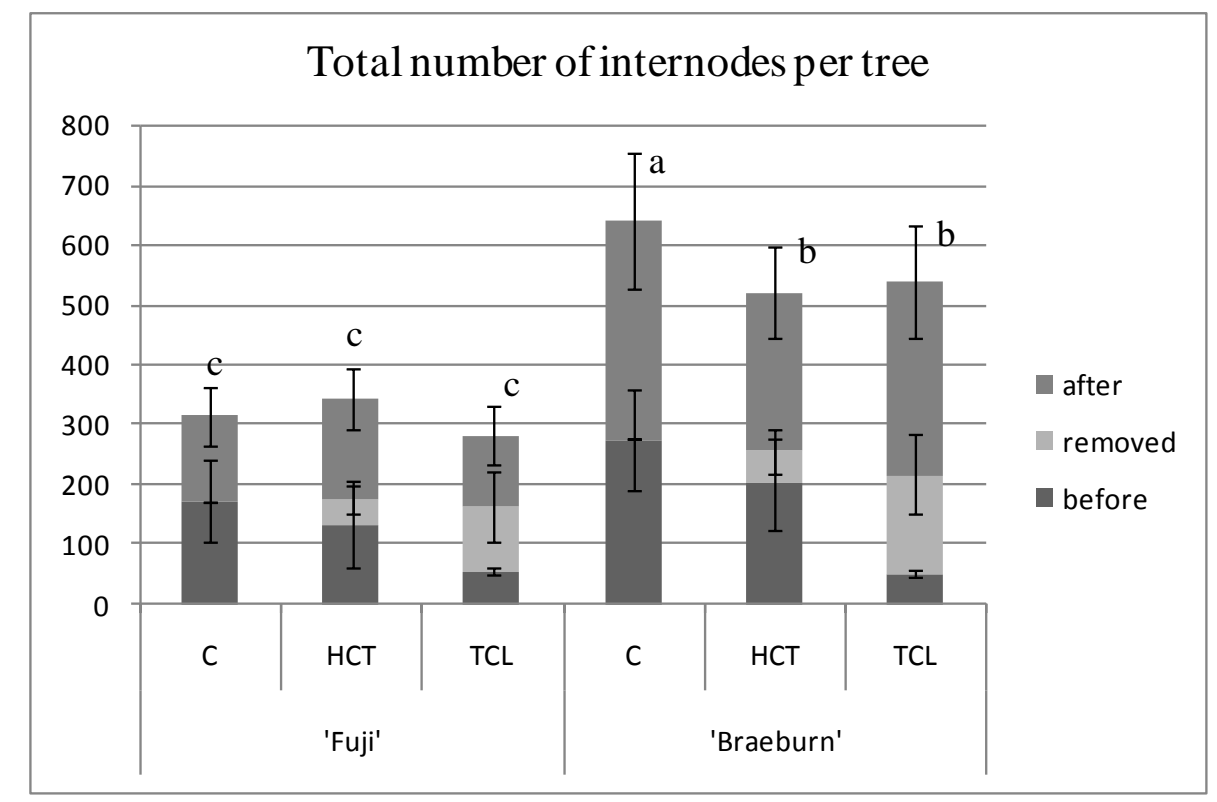

Fig. 2 Mean $( \pm$ SD) of total number of internodes per tree depending on the pruning treatment for 1-y-o trees of 'Fuji' and 'Braeburn' apple cultivars. Three internode categories were distinguished (cf. Fig. 1). A same letter indicates no significant difference between mean values according to the Newman-Keuls test.

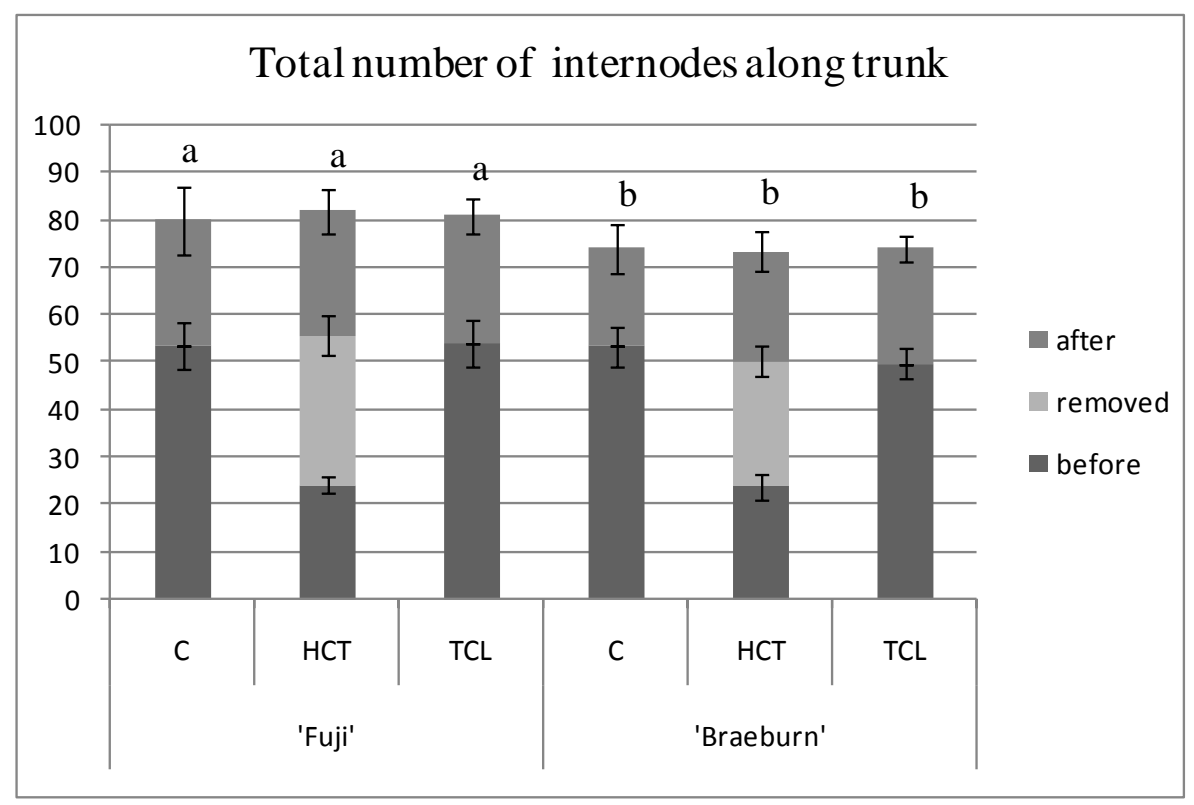

Fig. 3 Mean $( \pm$ SD) of number of trunk internodes per tree depending on the pruning treatments for 1-y-o trees of 'Fuji' and 'Braeburn' apple cultivars. Three internodes categories were distinguished (cf. Fig. 1). A same letter indicates no significant difference between mean values according to the Newman-Keuls test. For HCT, the internodes developed after pruning correspond to those developed on relay axis (cf. Fig. 1). 